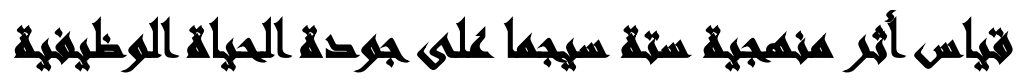 عراسما ميدانية
}

$[r \wedge]$

\author{
ممدوح عبد العزيز رفاعي(')- مصطفى حسن رجب(")- نهال محمد فتحي(")

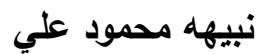

( ) كلية النجارة، جامعة عين شمس r) معهة الدراسات والبحوث البيئية، جامعة عين شس.

\section{المستخليس}

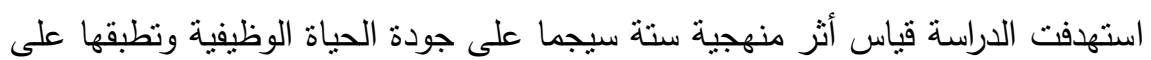

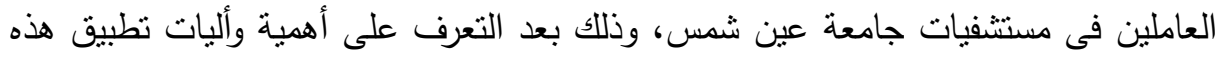

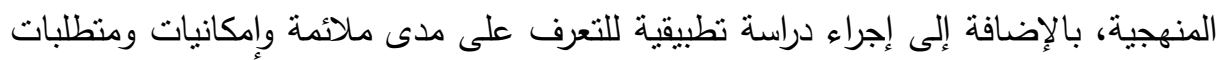

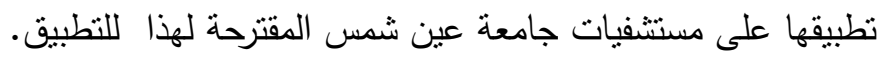

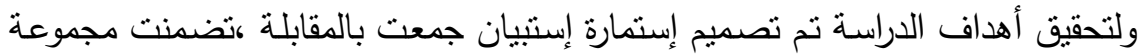

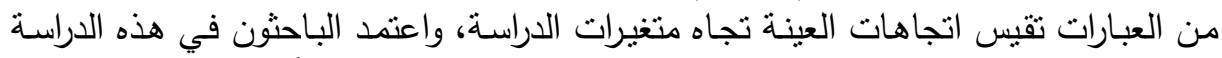

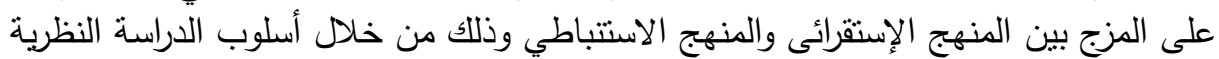

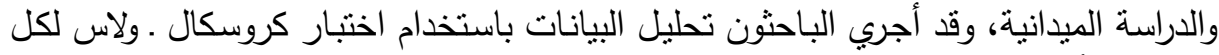

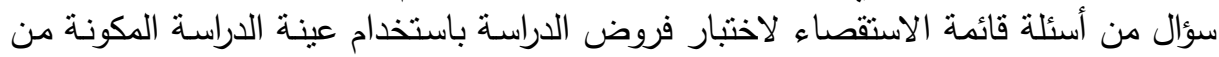

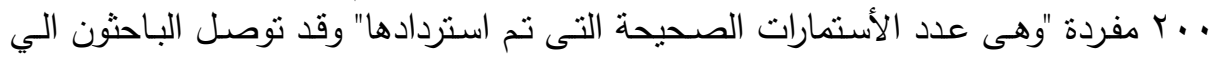
مجموعة من النتائج والتوصيات التي يمكن تطبيقها على المنشأة محل الدراسة (مستثفيات جامعة عين شمس). وقد توصلت الاراسة إلى: أن تطبيق منهجية ستة سيجما على مستشفيات جامعة عين شمس تؤوى إلى تحسين جودة الحياة الوظيفية. توصيات الاراسة:

ا ـ أهمية دور منهجية ستة سيجما لتحسين الجودة وخفض التكاليف بت جودة الحياة الوظيفية

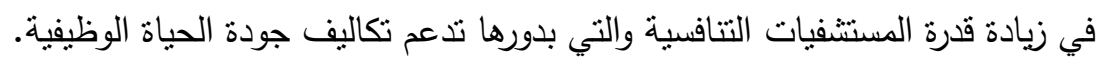

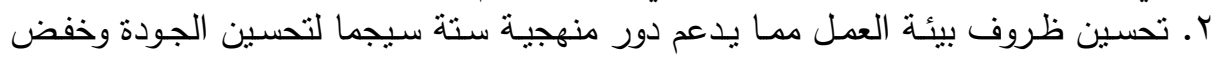
التكاليف، ومن ثم جودة الحياة الوظيفية. 
مجلة العلوم البيئية

معهد الدراسات والبحوث البيئية - جامعة عين شمس ليه

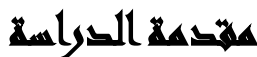

يعتبر المورد البشرى هو الثروة الحقيقية للمنظمات، لما له من تأثثر جوهرى على نجاحها وتطورها، فنتوقف قدرة المنظمات على تحقيق أهدفها بكفاءة وفاعلية على مدى كفاءة وفاعلية أداء العاملين بها والتى نتوقف بدورها جودة الحياة الوظيفية لهم، ولذللك أصبح

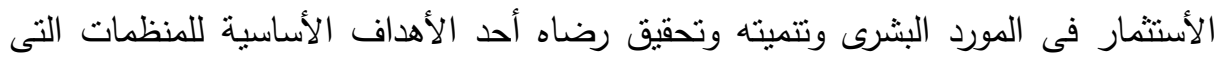

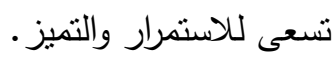

وتعد جودة الحياة الوظيقية من القضايا الإدارية التى احتلت مكاناً منميزاً فى أدبيات إدارة

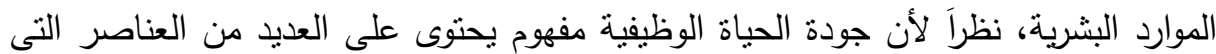
تمس أداء المنظمات مباشرة وتؤثر عليها وهذا المفهوم رغم انة قد يبدو مقصوراً على البيئة المباثرة للعمل، إلا أنه يلمس الحياة الثخصية للعاملين باعتبار أن الفرد هو كائن بشرى له له لهاء

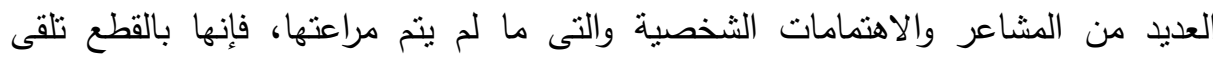

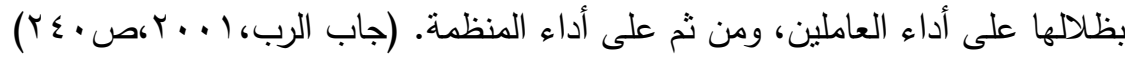

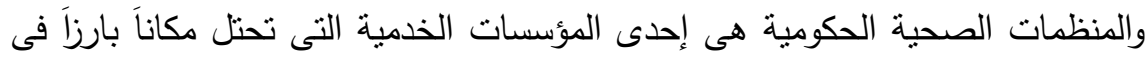
المجتمعات العربية لما تقدمه من خدمات صحية تمس حياة الإنسان،ولما لها من إنعكاسات مباشرة على المستوى الشخصى والجماعى، وأن حصول العميل على الخدمة بجودة عالية يعتبر من أهم عوامل النجاح للمنظمة ككل.

حيث أصبحت قضية الجودة من القضايا الملحة والمسيطرة على جميع المنظمات حول العالم مع زيادة حدة المنافسة و التغيرات الهائلة فى البيئة الخارجية للمؤسسات تعتبر المحرك

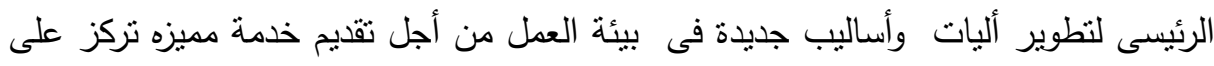

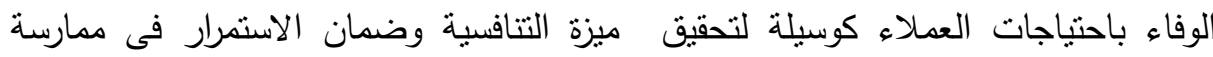
النشاط، وأدركت المنظمات أن عليها أن تهتم بالعملاء ومنطلباتهم لكى تحقق ميزة تتافسية

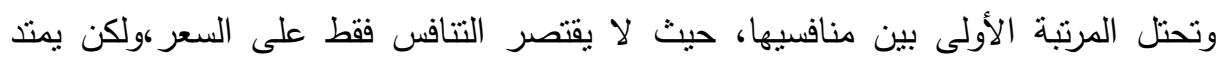

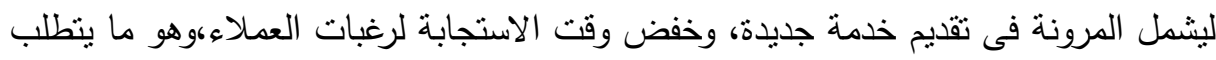
إجراء العديد من التغيرات فى عمليات وأنشطة المنظمات، وقد كان هذا الأمر يكلف المنظمات 
تكاليف عالية فى ظل تطبيق إدارة الجودة الثاملة،وهذا جعل المنظمات تبحث عن نظام جودة

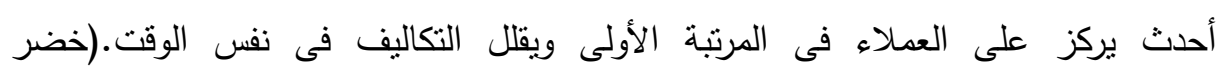

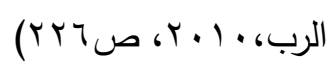

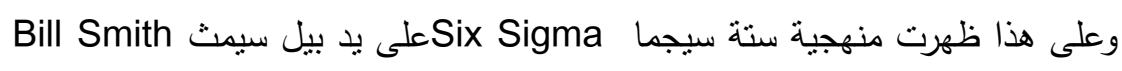

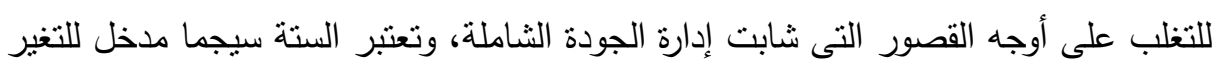
التتظيمى يضم عناصر إدارة الجودة الثاملة ،وإعادة هندسة العمليات، ومشاركة العاملين ويعمل على تقليل تكاليف الجودة المرتفعة. Motorola University,2007) يعرف(2005: Derrell S.ستة سيجما بأنها هيكل طويل الأجل لإستراتيجية تحسين

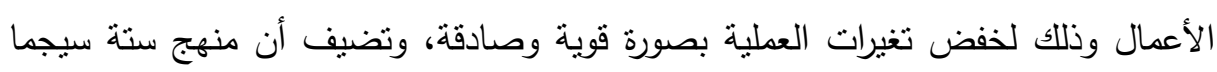
هو :

$$
\text { • • استرجية لتحسين الجودة. }
$$

ويضيف (Ferrin et al.,2003).أن منهج ستة سيجما قوبل بتقدير واسع كمنهجية وعملية وروية لإنجاز التحسينات فى العملية، فهو يعتمد على نركيز العميل، حيث أنها منهجية تعرف وتحدد وتحل الشكلة بطريقة جيدة ومدعمة من خلال أدوات إحصائية فعالة،كما تهدف إلى خفض التغيرات من خلال التحسين المستمر للعملية، كما إنها عملية عالية الدقة والتتظيم حيث نساعد على التركيز و التطوير للوصول بصورة تقريبية إلى منتجات وخدمات عالية الجودة،وستة سيجما كروية إحصائية مصطلح يقيس المسافة المعطاة للعملية

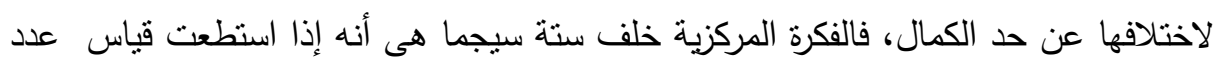
العيوب التى لديك فى العملية فإنك وبطريقة منتظمة سوف تحدد أو تكثف كم يمكن تجنبه من هذه العيوب فى العطلة، وأن تحقق عيوب صفرية كلما أمكن ذلك. ( Ferrin et (al.,2003 
ويعتبر المورد البشرى من أهم الموارد التى تعتمد عليها المنظمات لتحقيق أهدافها ورؤيتها الإستراتيجية، مما يتطلب معه التفكير فى كيفية الحفاظ على هذا المورد البشرى الهام وتطويره وتتميته حتى يؤدى عملة بكفاءة وفعالية، وطالما أن تتمية وتطوير المورد البشرى لئه

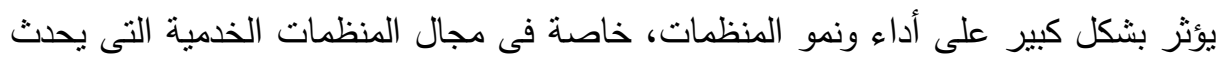

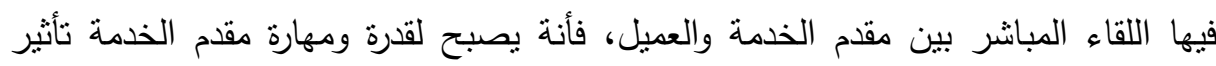

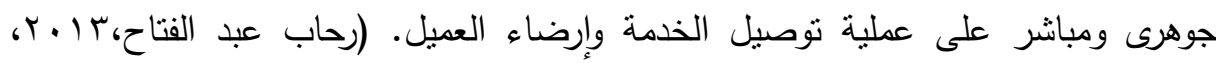

ويتحقق نمو المنظمات من خلال عملاء لديهم الولاء للمنظمة راضين عن القيمة المدركة

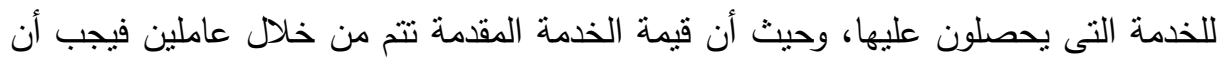
يتمتع هؤلاء العاملون بجودة الحياة الوظيفية التى تقدمها لهم منظماتهم، واهتمام الإدارة بأساليب وطرق تحفيز العاملين وتحقيق الرضا وتتمية الالتزام الوظيفى لديهم، يحقق تأثيراً

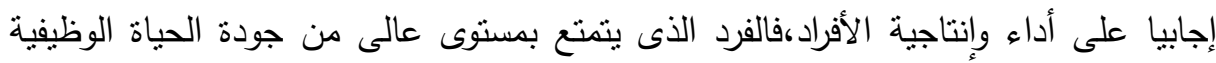
يحمل اتجاهات إجابية نحو وظيفته بينما الفرد الغير راضى عن وظيفته يحمل اتجاهات سلبيه

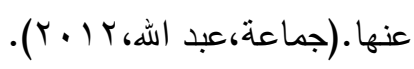
كما ترتبط جودة الحياة الوظيفية بالعديد من نتائج ومخرجات العمل الهامة منل الالتزام

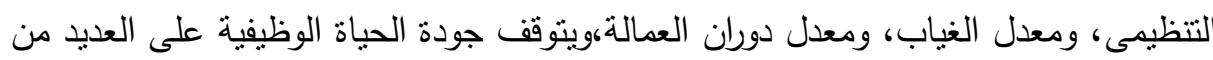
المتغيرات والتى من أهمها مدى جودة العلاقات بين المنظمة والعاملين بها. (أبومازن، (ะTrur. 1)

لذا فإن هذا البحث هو محاولة لدراسة تأثثر استخدام منهجية ستة سيجما على جودة

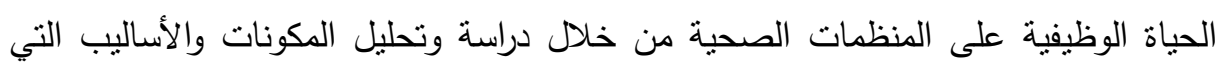

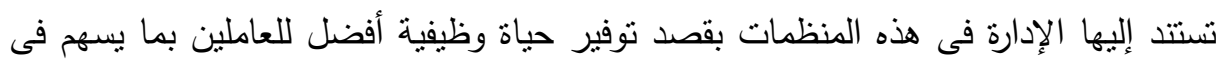

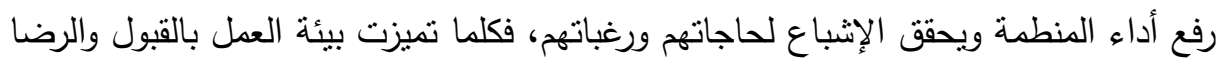
من العاملين، ساهم ذلك فى جعل الأفراد مستغرقين بشكل أفضل فى وظائفهر ما يؤدى فى أتى النهاية إلى أداء متميز للخدمة الصحية. 


\section{همحلة التراسلة}

يعتبر قطاع الصحة من القطاعات الهامة والرئيسية والأكثر حيوية فى أى دولة، لاهتمامه بأغلى وأثمن ما يمتلكة أى فرد وهى الصحة، والتى تعتبر من أهم المتطلبات

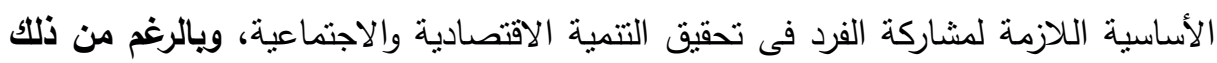
يعانى القطاع الصحى الحكومى من مجموعة الظواهر التى تؤثر سلبا على الحياة الوظيفية للعاملين والتى من أهمها. • الخلل فى العلاقات الإنسانية فيما بين الأطباء وبعضهم من جهة، والفئات الأخرى من الفنيين والإداريين والمرضى من جهة أخرى. • مقاومة التغيير وعدم القدرة على التكيف مع المستجدات والتطورات البيئية الداخلية والخارجية.

• إستناء الأفراد والمرضى المتعاملين مع المستشفيات الحكومية من أداء مقدمى الخدمة الصحية. • الإهمال نتيجة ضعف نظم الحوافز والرقابة ومتابعة الأداء ومركزية السلطة،وعدم تفويضها مما ينعكس سلبا على الروح المعنوية للعاملين وبالتالى على أدائهم. كما تشير نتائج الاراسات: • سوء معاملة وإهمال المشرفين بتلك المسنشفيات لمرؤوسهم.

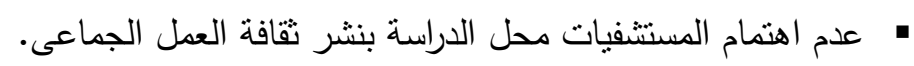

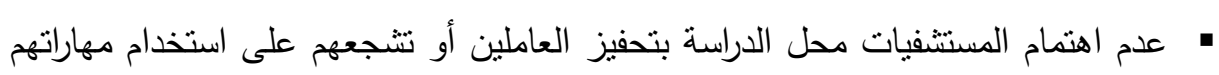
وقدراتهم.

• رغبة المديرين فى الإنفراد بالسلطة تجعلهم لا يقومون بتبنى وتتجيع العاملين الموهوبين على الابتكار و التجديد وتتمية الأفراد لتكوين قيادات المستقبل.

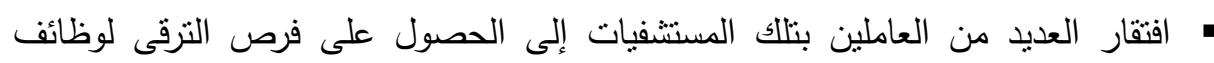

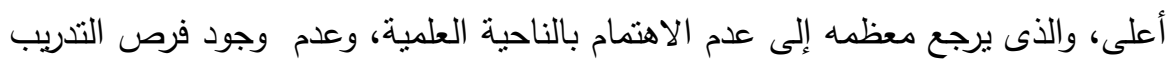


من الظواهر السابقة وغيرها مما يتعلق بأبعاد جودة الحياة الوظيفية يمكن القول أن تأثيرها سيكون سلبا على درجة استغراق العاملين فى وظائفهم،والخروج بخدمة لا تنميز

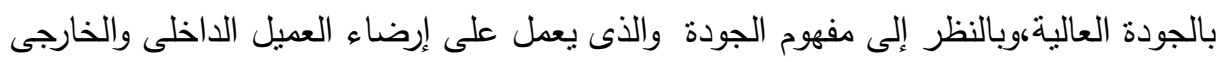
وليس العميل الخارجى فقط ، ولكن فى الواقع معظم المنظمات الصحية (المستشفيات) تهنم بالعميل الخارجى فقط (المرضى) دون الاهتمام بالعميل الداخلى وهم (العاملين) داخل فئل الوحدات الصحية، ومن ثم فإن فاقد الثئ لا يعطية، فإذا كنا نريد تقديم خدمة تنميز بالجئ بالجودة العالية لا بد من الاهتمام بجودة الحياة الوظيفية للعاملين بالمنظمة محل الدراسة. وهناك من الاراسات التى قامت بتطوير منهجية ستة سيجما ليمكن تطبقها فى المجالات

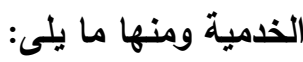

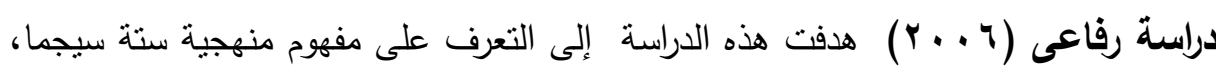
ومدى قدرة تطبيقها فى المنظمات الخدمية، بقطاع البنوك المصرية، وكذلك هدفت إلى معرفة هده مدى توافر المقومات اللازمة فى هذه المنظمات لنطبيق الستة سيجما والعلاقة بين تطبيقها

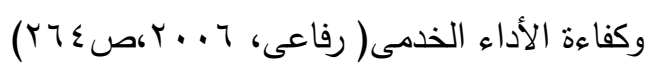
وتوصلت الدراسة إلى عدة نتائج أهمها: ا. منهج ستة سيجما يؤدى إلى تحقيق الجودة أى وفعالية الأداء ويقاس ذلك من خداء الدال قياس أبعاد جودة الخدمة المصرفية لأن المحصلة النهائية هى المخرجات. r. منهج استبعاد الفاقد Leen Approach يؤدى إلى خفض التكاليف أى (كفاءة الأداء)

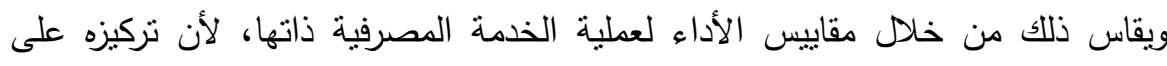
العملية. r. يكون محور القياس فى المحور الأول هو العميل،وفى المنهج الثانى هو الموظف (مقدم الخدمة).

وينم تنظيم الستة سيجما حول مشروعات فردية ذات نوقيتات زمنية محددة، ويبدأ كل مشروع بتكوين فريق للتعرف على احتباجات العملاءويقوم الفريق بقياس كيف يمكن الوفاء 
بهذه الاحتباجات وتحليل المتغيرات التى تؤثر على إرضاء العميل،وكيفية تحسين رقابة العملية.

لذا قامت الباحثة باستخدام منهجية ستة سيجما Six Sigma لمحاولة التغلب على المشاكل السابق ذكرها لتحسين جودة وخفض تكاليف جودة الحياة الوظيفية للعاملين بمسنتفيات جامعة عين شمس محل الدراسة".

\section{أسئلا الصوراسلا}

ما أثر تطبيق منهجية ستة سيجما على جودة الحياة الوظيفية للعاملين بمستثفيات جامعة عين شمس؟ وينبثق من هذا التسأل الرئيسى التساؤلات الفرعية التالية

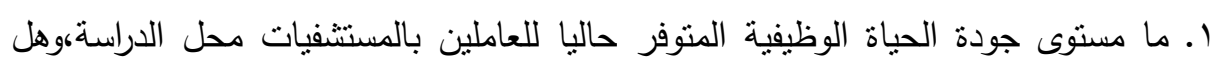
يختلف هذا المستوى بين الفئات المختلفة الجوهرية العاملة بالإدرات والقطاعات المختلفة

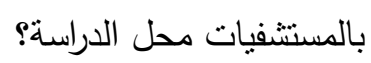
r. إلى اي مدى يوجد إختلاف فى مستوى جودة الحياة الوظيفية لكل من الفئات المختلفة

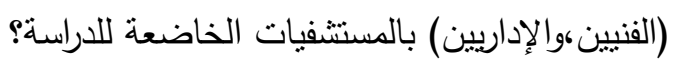
r. ما أثز استخدام منهجية ستة سيجما فى خفض تكاليف جودة الحياة الوظيفية؟ بالئهين ع. ما تأثير منهجية ستة سيجما على تحسين جودة الحياة الوظيفية؟ وما هو مردود هذا التأثير على الخدمة الصحية؟ ماله

\section{أهمانهـ الصراسها}

يتمثل الهذف الرئيسى للاراسة فى التوصل إلى"إطار مقترح لقياس أثز منهجية ستة

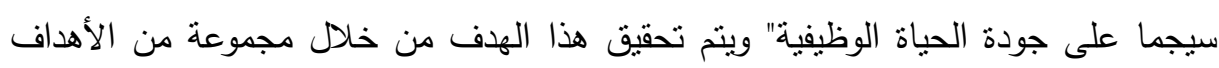

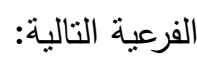
ا ـ دراسة هدى ثأثثر جودة الحياة الوظيفية على أداء العاملين فى المستشفيات محل الدراسة. r. تحليل مدى نأثثير كل بعد من أبعاد جودة الحياة الوظيفية على العاملين بالمستشفيات محل الدراسة.

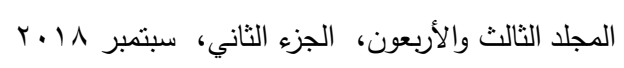


r. التعرف على مدى نأثير منهجية ستة سيجما على تكاليف جودة الحياة الوظيفية ومدى حجم وطبيعة هذا التأثنر . كاني ع. دراسة الاختلاف بين أراء عينة الدراسة حول متغيرات الدراسة تعزى للمتغيرات الديموغرافية المتمثلة فى (النوع- السن -المستوى الوظيفى).

\section{أهمرة القورامة}

تتمثل أهمية الدراسة فى جانبين العلمى (الأكاديمى) والجانب (التطبيقى). الأهمية العلمية للاراسة: تتمنل أهمية الدراسة من الناحية العلمية فى الموضوع الذى الذى تتتاوله الدراسة حيث يتم التعرض لموضوع معاصر، فهناك ندرة فى عدد الدراسات السابقة

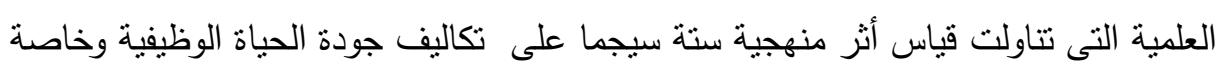

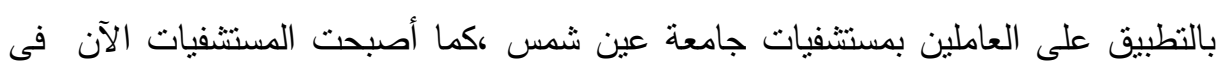

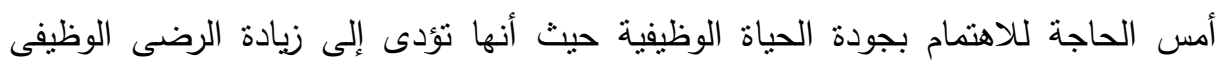

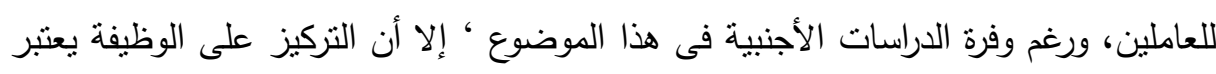
أحد الركائز الأساسية التى تسعى المنظمات لتحقيقها وهى جودة الحياة الوظيفية كأحد المداخل

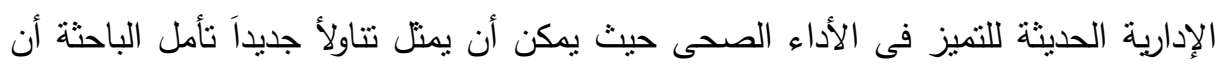
يكون إضافة للمكتبة العربية.

\section{الأهمية العملية (التطبيقية):}

1- يعتبر قطاع الصحة من القطاعات الهامة والرئيسية والأكثر حيوية فى أى دولة، وبعتبر

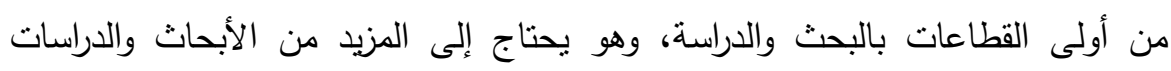

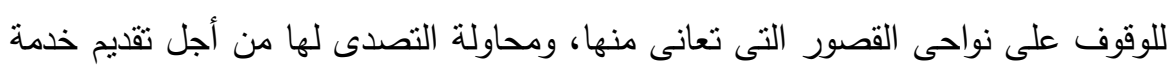

$$
\text { صحية متميزة للمواطنين. }
$$

r- تحتل المستشفيات الحكومية بصفة عامة،والمستشفيات الجامعية بصفة خاصة أهمية متميزة من بين مستشفيات القطاع الصحى، نظرا لمساهمتها فى تقديم الخدمات العلاجية 
والوقائية، والتعليمية لأفراد المجتمع، واستفادة أعداد كبيرة من المرضى المستقيدين من الخدمة الصحية المقدمة لهم.

r- تقديم مجموعة من التوصيات بالإضافة إلى مقترح تطبيقى للتطوير التنظيمى للمستشفيات من أجل رفع مسنوى جودة الحياة الوظيفية باستخدام أحد المناهج الإدارية الحديثة

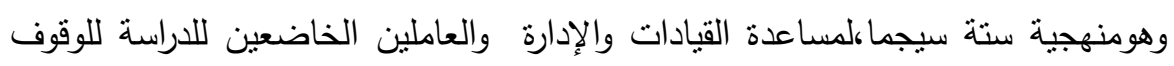

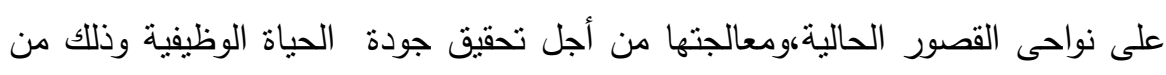
أجل تقديم خدمة صحية متميزة، والتى تعود بالنفع على المجتمع المستفيد من الخدمة الصحية.

\section{التراسايت السارية}

قامت الباحثة بتتاول أهم الدراسات السابقة العربية والأجنبية المتعلقة بمشكلة الدراسة فى

$$
\text { ضوء ما توافر لها وذللك على النحو التالى: }
$$

\section{1-الاراسات السابقة العربية والأجنبية الخاصة بجودة الحياة الوظيفية وتناولت الباحثة فيما}

يلى أهم هذه الاراسات طبقاً للتسلسل التاريخى.

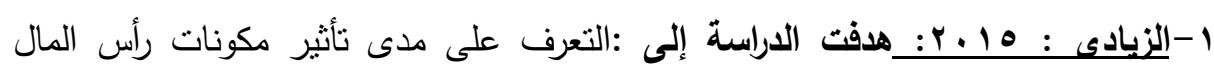

الفكرى وأبعاد جودة الحياة الوظيفية على تعزيز القدرات التتافسية للموارد البشرية.

$$
\text { توصلت الدراسة إلي مايلى: }
$$

1- قبول الفرض البديل وهو يوجد تأثثر معنوى ذو دلالةقإحصائية بين مكونات رأس المال

$$
\text { الفكرى وبين تعزيز القدرات التتافسية للموارد البشرية. }
$$

r-قبول الفرض البديل وهو يوجد تأثثر معنوى ذو دلالة إحصائية بين أبعاد جودة الحياة

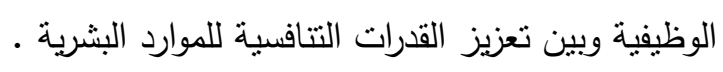

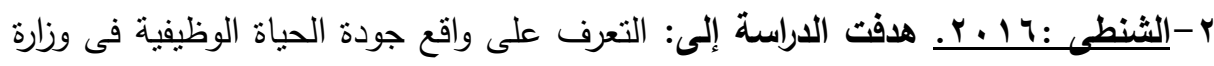
الأشغال العامة والأسكان وعلاقتها بأخلاقيات العمل لدى موظيفى وزارة الأشغال العامة 
توصلت الدراسة إلى ما يلى:

ا-توجد علاقة إيجابية بين جودة الحياة الوظيفية وأخلاقيات العمل لدى العاملين فى وزارة

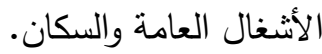

r-تتوافر جودة الحياة الوظيفية فى وزارة الأشغال العامة الإسكان بدرجة متوسطة

الاراسات الأجنبية المتعلقة بجودة الحياة الوظيفية.

Indumathi \&SeIvan 2014 .1

هدفت الاراسة إلى: التعرف على دور جودة الحياة الوظيفية فى تحسين الأداء التتظيمى وتحقيق رضا العاملين.

توصلت الدراسة إلى: أن أهم العوامل التى تسهم فى تحقيق جودة الحياة الوظيفية هى تحقيق

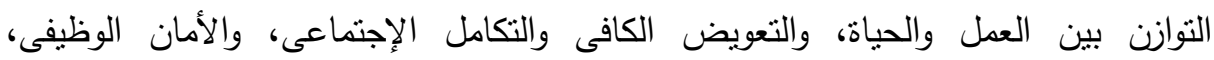

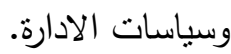

2015 John . ${ }^{r}$ هدفت الدراسة إلى: التعرف على العلاقة مابين أداء العاملين فى بيئة العمل الصناعية وادراكهم لجودة الحياة الوظيفية توصلت الدارة إلى:.وجود علاقة إجابية معنوية ما بين نطبيق مفهوم جودة الحياة الوظيفية

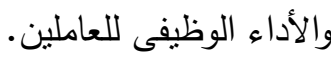
الاراسات السابقة المتعلقة بمنهجية ستة سيجما. ا-دراسة رفاعى Y . . Y هدفت الدراسة إلى: التعرف على إثثين من منهجيات التحسين

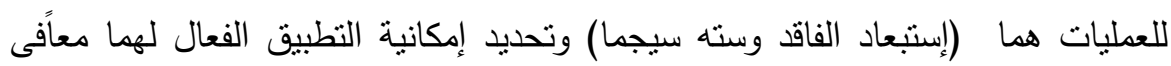
القطاع المصرفى. وتوصلت الدراسة إلى عدة نتائج أهمها:

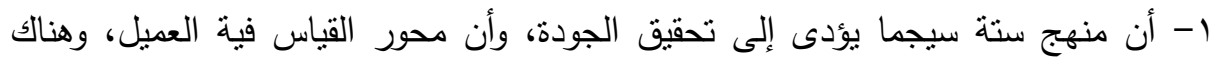
تثابه بين أدواته وأدوات إدارة الجودة الكلية، وهو يهتم بقياس فعالية الأداء من خلال قياس

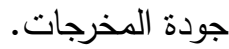


r- منهج إستبعاد الفاقد يؤدى إلى خفض التكلفة،وأن محور القياس فيه هو العاملين، ويهتم

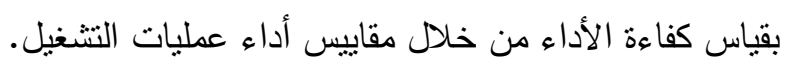

r- أوصت الدراسة بتنبى منهجية ستة سيجما ومهنجية إستبعاد الفاقد، والتركيز على أدواتهم لحل مشكلات العمليات، مع ضرورة وضع مؤشرات منوازنة لقياس فعالية أداء العاملين.

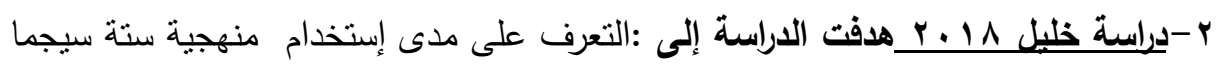
فى تحسين جودة الأداء فى المصار ف الأهلية العراقية.

توصلت نتائج الدراسة إلى: أن هناك علاقة إرتباط بين نطبيق منهجية ستة سيجما وتحسين الأداء

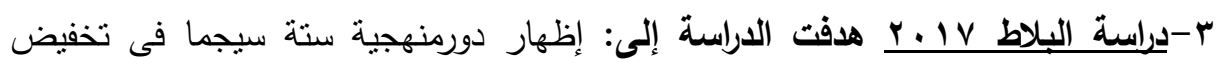
تكاليف الجودة،وذذلك من أجل تحقيق التتافسية. توصلت نتائج الدراسة إلى: أن هناك علاقة إرتباط بين نطبيق منهجية ستة سيجما وتخفيض

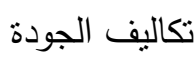

\section{الدراسات الأجنبية المتعلقة بمنهجية ستة سيجما.}

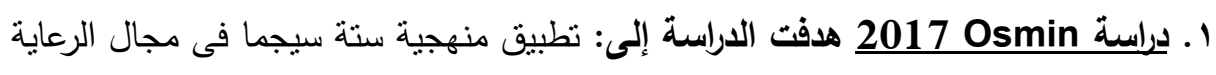

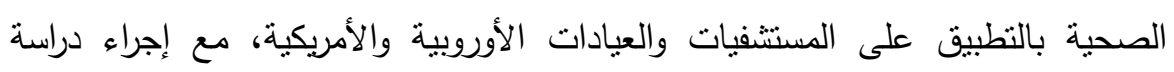
مقارنة قبل وبعد تطبيق منهجية ستة سيجما على المنشأت محل الدراسة. توصلت نتائج الدراسة: - أن تطبيق منهجية ستة سيجما يحسن من الأنشطة اليومية فى المستشفيات، مما يؤدى إلى لى التحسين المستمر فى تقديم الخدمة الصحية المقدمة. - أن تطبيق منهجية ستة سيجما يؤدى إلى زيادة رضا العملاء، وزيادة كفاءة العاملين، وتزيد من ربحية المستشفيات.

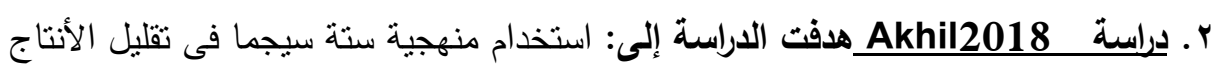
المعيب، وخفيض التكاليف فى صناعة النظارات الطبية.

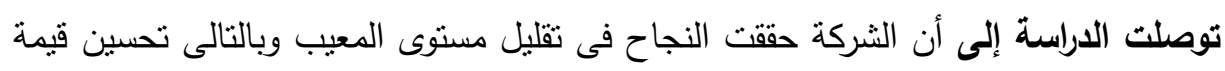

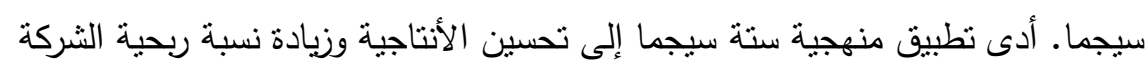

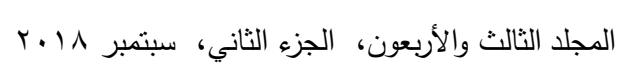




\section{الإسار اللنظليهى}

تتمل الدراسة على عدد من المفاهيم التي لابد من توضيحها وتحديد المقصود منها وهي على

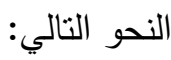

ا ـ تعرف منهجية ستة سيجما. بأنها منهجية علمية للتحسين المستمر يتم تطبيقها من خلال خمس مراحل محددة من العمل المنظم، في كل مرحلة يتم تتفيذ مجموعة من الأنشطة،

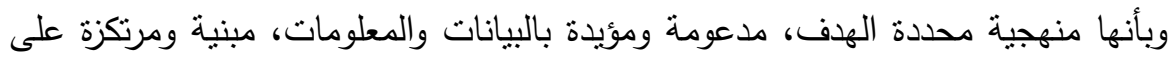

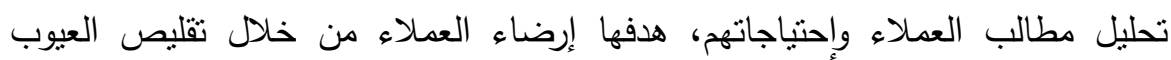
ومحاولة تفاديها، وتقليل الأخطاء والعمل على تلافيها سواء في عمليات الإنتاج أو في

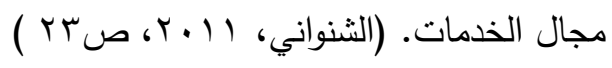

r. تعرف جودة الحياة الوظيفية. بأنها توفير بيئة عمل مناسبة للعاملين بالمنظمة لمساعدتهم

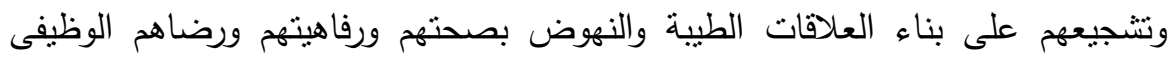
وتتمية كفاءاتهم والتوازن بين العمل والحياة خارج نطاق أعمالهم مما يؤثر على الأداء الوظيفى الكلى ( Pavithra and Barani:2012pp,67) r. مفهوم تكاليف جودة الحياة الوظيفية: هى نلك النفقات التى تتحملها المنظمة من أجل تحسين جودة الحياة الوظيفية.

\section{هنهمج الصواسلة}

فى ضوء طبيعة المشكلة وهدف وأهمية الدراسة أعتمدت الباحثة على منهجين أساسيين فى أعداد الدراسة هما:

1-المنهج الوصفي التحليلي: حيث قامت الباحثة بالإطلاع وإستقراء الدراسات العلمية التى تتاولت موضوع الدراسة من خلال إتباع أسلوب الدراسة المكتبية والإطلاع على المراجع العلمية المتخصصة العربية والأجنبية من كتب علمية ومقالات منشورة بالمجلات العلمية المحكمة والدوريات المختلفة وما صدر من المؤتمرات العلمية ورسائل علمية والدراسات السابقة وأبحاث مرتبطة بموضوع الدراسة والمتعلقة بالمشكلة موضوع الدراسة. 
r- المنهج التطبيقى: استخدمت الباحثة هذا المنهج بهدف الكثف عن النتائج المنطقية المترتبة على إختبار الفروض الأساسية للاراسة ،وذذلك من خلال القيام بدراسة ميدانية تهدف إلى إختبار فروض البحث السابقة، وذلك من خلال بيانات مستمدة من قائمة

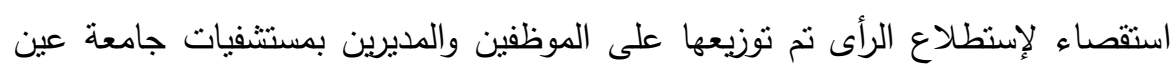

شمس.

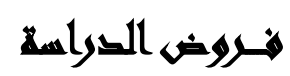

من أجل تفسير إثكالية الدراسة ومحاولة الإجابة عن الأسئلة المطروحة يمكن صياغة

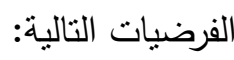

الفرض الأول: يوجد أثز جوهري لنطبيق منهجية ستة سيجما على جودة الحياة الوظيفية.

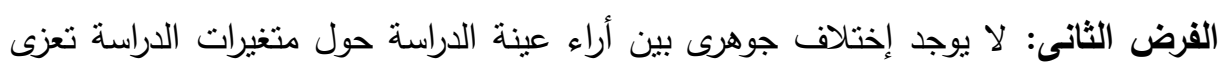
للمتغيرات الديموغرافية المتمثلة فى (النوع- السن -المستوى الوظيفى).

\section{إجبراعاهي التصاسمة}

الدراسة الميانية (المنهج التحليلي):اعتمد الباحثون في إجراء الدراسة الميدانية على قائمة الاستقصاء والتي تم نوزيعها على عينة من المديرين والعاملين بمستشفيات جامعة عين شمس، وذلك في الفترة من ب/T/1 0 ورغباتهم واتجاهاتهم والعناصر الغير مرضية التى تواجهم وانطباعاتهم واقتراحاتهم، وقد نم

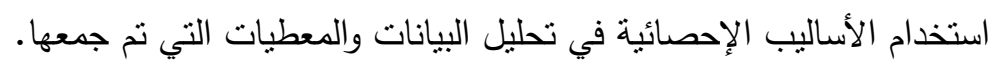

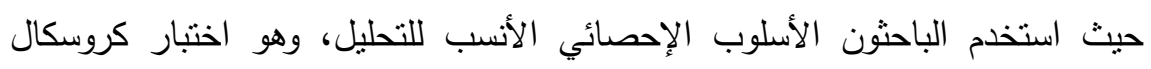

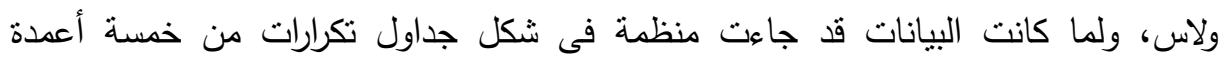
وصفين، تمثل الصفوف عينة الدراسة (المديرين والموظفين بمستشفيات جامعة عين شمس) وتمثل الأعدة استجابات الأفراد على أسئلة الاستقصاء والتى نم ترتيبها تتازلياً من موافق وائق تماماً إلى لا أوافق مطلقاً. 


\section{أسلوب وأدوات الاراسة:}

أ- مجتمع الدراسة والعينة: يمكن توضيح كلاً من مجتمع وعينة الدراسة كما يلي: مجتمع الدراسة: يتمثل مجتمع الدراسة من المديرين والعاملين بمستشفيات جامعة عين شمس

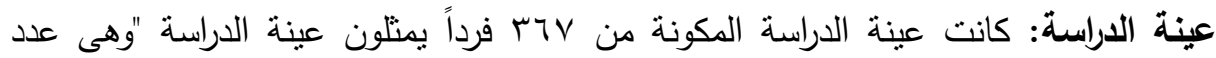
الاستمارات الصحيحة التى نم استردادها"من (المديرين والعاملين بمستشفيات جامعة عين

ونظراً لطبيعة البيانات التى تتسم بندرة الاستجابة على بعض فئات الاستجابة خاصة فئة لا أوافق مطلقاً، فقد قام الباحثون بحساب قيمة كروسكال ـ ولاس بإستخدام برنامج " Statxact 4.0 ونم اختبار معنوية قيم كروسكال .ولاس لكل سؤال عند مستوى 0 .,..

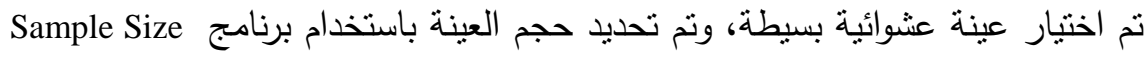
\% Calculator

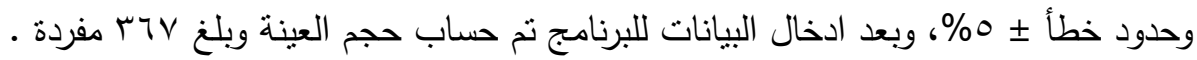
ب- قياس متغيرات الدارةة: في ضوء الدراسات السابقة التي إطلع عليها الباحثون، فقد اعتمد الباحثون فى قياس المتغير المستقل (منهجية ستة سيجما ) والمتغير التابع (جودة التهاء

الحياة الوظيفية).

ج- أداة تجميع بيانات الاراسة الميدانية: قام الباحثون بتصميم قائمة استقصاء لتجميع البيانات من مفردات البحث، حيث مر إعدادها وتصميمها بالخطوتين التاليتين:

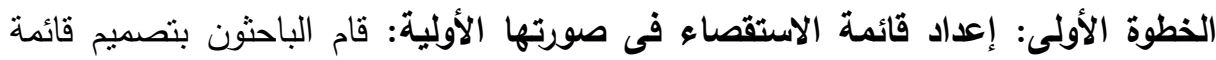
استقصاء أُعدت خصيصاً لقياس متغيرات الدراسة (منهجية ستة سيجما لتحسين الجودة وخفض التكاليف (المتغير المستقل الرئيسي) وأبعادها -والمتغير التابع الأول: (جودة الحياة

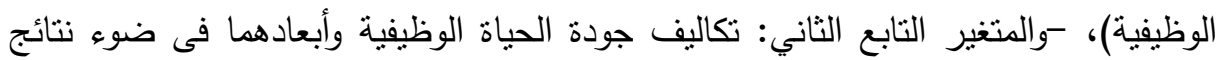
بعض البحوث والدراسات والكتابات العلمية السابقة، وكذللك فى ضوء ما كثفت عند عنه نتائج الدراسة الاستطلاعية. 
وقد تم صياغة عبارات الاستقصاء بأسلوب خبرى وبألفاظ سهلة وبسيطة حتى تتفق مع

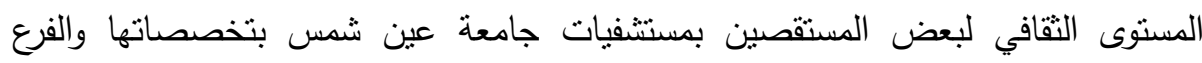
الرئيسي موضع الدراسة، هذا وقد بلغ عدد هذه العبارات اثثين وسبعون عبارة.

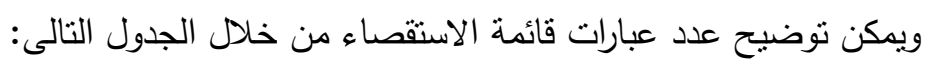

جدول: عدد عبارات قائمة الاستقصاء حسب متغيرات الدراسة

\begin{tabular}{|c|c|c|}
\hline عدد العبارات & عدد المتغيرات الفرعية & متغيرات الاراسة \\
\hline$r \cdot$ & $\varepsilon$ & منهجية ستة سيجما لتحسين الجودة وخفض التكاليف \\
\hline r & 0 & جودة الحياة الوظيفية \\
\hline r) & r & تكاليف جودة الحياة الوظيفية \\
\hline VY & ir & أجمالى \\
\hline
\end{tabular}

المصدر: من إعداد الباحثة

الخطوة الثانية: اختبار صدق وثبات الاستقصاء: وقد قام الباحثون باختبار قائمة الاستقصاء

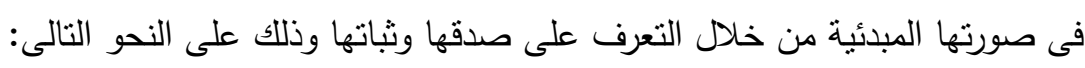
ه اختبار صدق الاستقصاء: اعتمدت الباحثة على صدق مفردات الدراسة الميدانية، وذلك

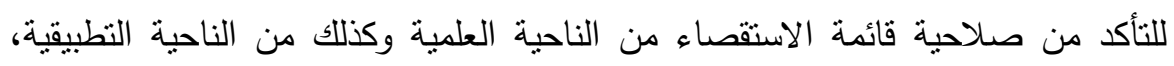

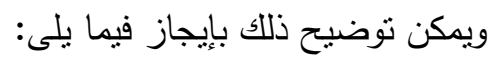

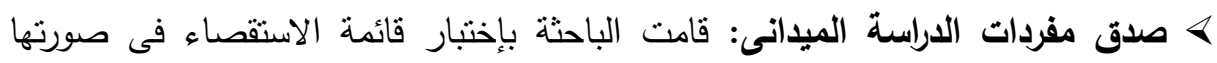
المبئية من خلال التعرف على صدقها وثباتها وذلك على النحو التالى:

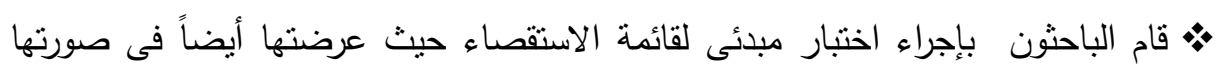

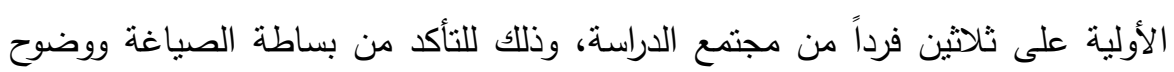
اللغة، وللتأكد أيضاً من صلاحية الاستقصاء من الناحية المنيد الميدانية.

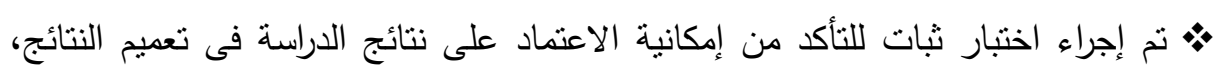

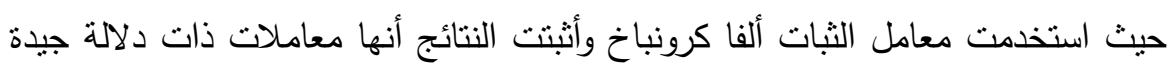
لتحقيق أهداف الدراسة بعد استبعاد بعض العبارات، ويمكن الاعتماد عليها فى تعميم النتائج على مجتمع الدراسة. • خ حساب معاملي الصدق والثبات . 
مجلة العلوم البيئية

معهد الدراسات والبحوث البيئة - جامعة عين شمس

جدول معاملى الثبات لألفا كرونباخ والصدق الذاتى لاستمارة الاستقصاء

\begin{tabular}{|c|c|c|c|c|}
\hline معامل الصدق الذاتى & $\begin{array}{l}\text { معامل الثبات } \\
\text { (Alpha) }\end{array}$ & 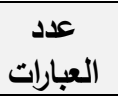 & البيـان & المحاو \\
\hline 0.938 & 0.88 & $20 / 4$ & وخفضية ستة سيجما لتحسين الجودة & الأول \\
\hline 0.912 & 0.831 & 5 & خطوات منهجية ستة سيجما & 1 \\
\hline 0.850 & 0.722 & 5 & تطبيق منهجية ستة سيجما & $r$ \\
\hline 0.939 & 0.842 & 5 & أدوات ستة سيجما & $r$ \\
\hline 0.981 & 0.963 & 5 & مقاييس ستة سيجما & $\varepsilon$ \\
\hline 0.988 & 0.976 & $31 / 5$ & جودة الحياة الوظيفية & 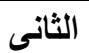 \\
\hline 0.860 & 0.740 & 6 & ظروف بيئة العمل & 1 \\
\hline 0.973 & 0.946 & 7 & الخصائص الوظيفية & r \\
\hline 0.960 & 0.907 & 6 & جماعة العمل & $r$ \\
\hline 0.864 & 0.940 & 6 & أسلوب الرئيس فى الأشراف & $\varepsilon$ \\
\hline 0.864 & 0.967 & 6 & المشاركة في إتخاذ القرارات & - \\
\hline 0.988 & 0.977 & $21 / 3$ & تكاليف جودة الحياة الوظيفية & 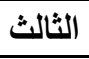 \\
\hline 0.974 & 0.949 & 7 & خفض تكاليف الاختيار والتعيين & 1 \\
\hline 0.896 & 0.802 & 7 & خفض تكاليف التدريب & r \\
\hline 0.972 & 0.945 & 7 & خفض تكاليف المكافأت والحوافز المادية & $r$ \\
\hline
\end{tabular}

المصدر: من إعداد الباحثة من واقع مخرجات برنامج SPSS V25.

وباستعراض الجدول رقم (1) يتضح أن قيم معامل الثبات مقبولة لجميع المحاور ، حيث ليث تضمنت استمارة الاستقصاء ثلاثة محاور رئيسية وكل محور يتكون من مجموعة من الأبعاد

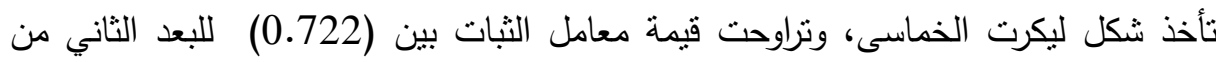
المحور الأول " تطبيق منهجية ستة سيجما " و (0.977) للبعد الثالث " تكاليف جودة الحياة

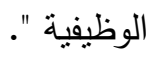

وتراوحت قيمة معامل الصدق بين (850 ـ0) للبعد الثاني من المحور الأول " تطبيق

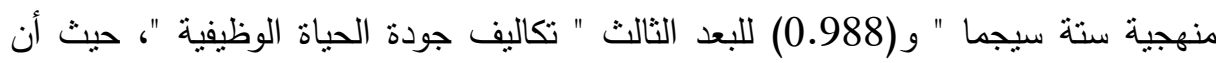
قيمة معامل الصدق الذاتى هى الجذر التربيعى لقيم معامل الثبات، لبهات 712

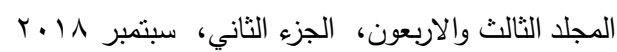


ومن خلال قيمة معاملات الثبات والصدق يمكن القول أنها معاملات ذات دلالة جيدة

لتحقيق الهدف من الدراسة ويمكن الاعتماد عليها فى تعميم المخرجات على المجتمع ككل.

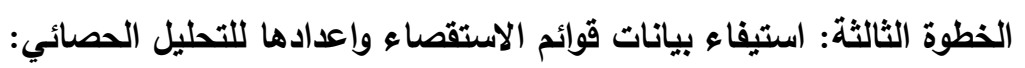

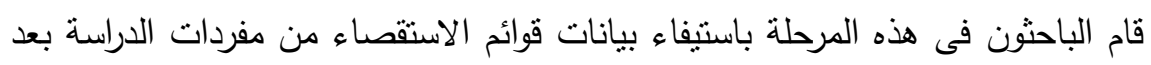

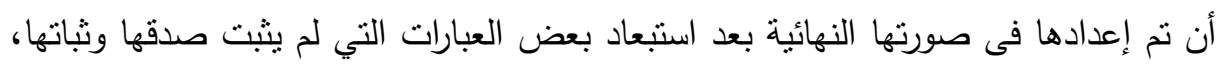

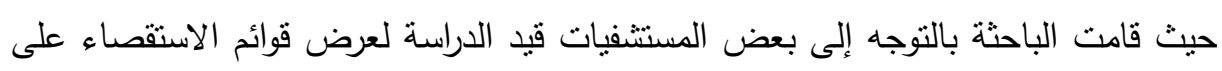
بعض العاملين عن طريق المقابلات الثخصية التى أجرتها معهم.

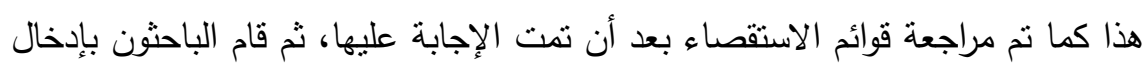

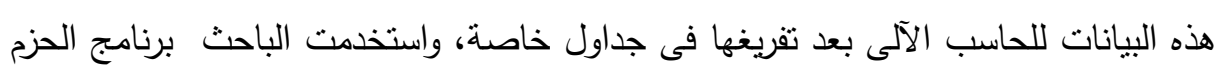
الإحصائية (SPS V25) فى إجراء التحليل الإحصائى لبيانات الدراسة الميدانية، وذلكانك بالاستعانة بمكتب متخصص بالدراسات والتحليل الإحصائي. أساليب التحليل الإحصائي: اعتمد الباحثون على الأساليب التالية:

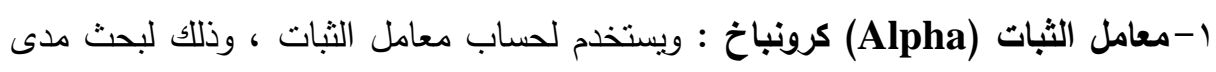
إمكانية الاعتماد على نتائج الدراسة الميدانية فى تعميم النتائج.

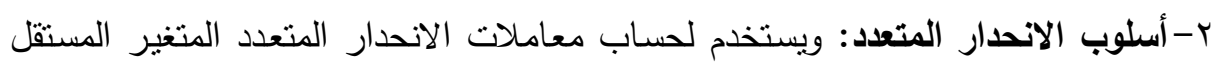

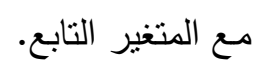
r-اختبار كروسكال ـ ولاس "Kruskal Walias Test : أحد الاختبارات اللامعلمية التي تستخدم لاختبار الفرق بين متوسطين.

إن أنسب الاختبارات الإحصائية لهذا الشكل من البيانات هو اختبار كروسكال ـ ولاس Kruskal Walias Test" القائل بعدم وجود فروق بين الصفوف الثلاثة (عينة الدراسة) فى استجاباتهم على أسئلة

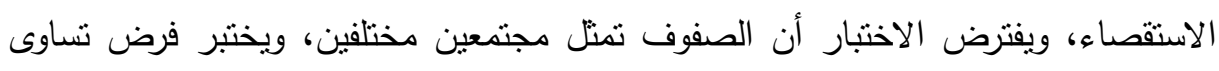

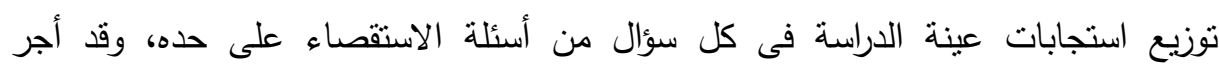
الباحثون تحليل البيانات باستخدام اختبار كروسكال ولاس لكل سؤن سؤال من أسئلة قائمة الاستقصاء لاختبار فروض الدراسة.

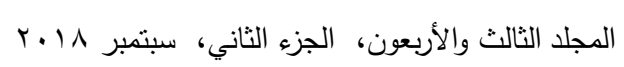


واستخدم الباحثون برنامج الحزم الإحصائية (SPSS) فى إجراء التحليل الإحصائي لبيانات

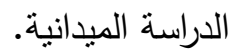

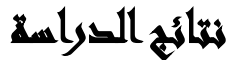

اختبارات الفروض وتحليل النتائج: ويتتاول الباحثون كل عنصر من العناصر السابقة

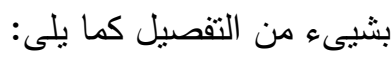
() اختبار الفروض وتحليل النتائج: "لا يوجد أثر جوهري لأبعاد منهجية ستة سيجما على

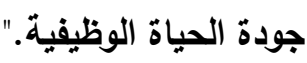
ويشتق من هذا الفرض الفروض الفرعية التالية: 1- لا يوجد أثز جوهري لخطوات منهجية ستة سيجما على جودة الحياة الوظيفية. r- لا يوجد أثر جوهري لتطبيق منهجية ستة سيجما على جودة الحياة الوظيفية. r- لا يوجد أثز جوهري لمقاييس ستة سيجما علي جودة الحياة الوظيفية. ع - لا يوجد أثز جوهرى لأدوات ستة سيجما علي جودة الحياة الوظيفية. لاختبار هذا الفرض تم استخدام الأساليب الاحصائية الآتية: - معاملات الارتباط لبيرسون بين أبعاد منهجية ستة سيجما وأبعاد جودة الحياة الوظيفية.

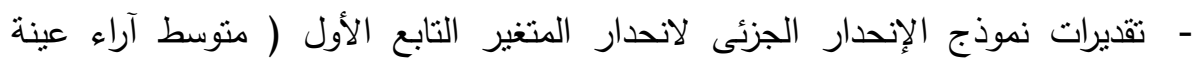

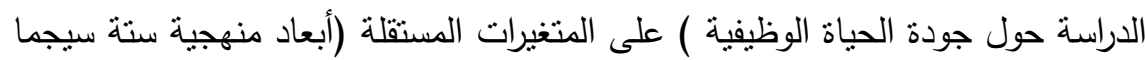

$$
\text { لتحسين الجودة وخفض التكاليف). }
$$

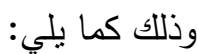

\section{> معاملات الارتباط لبيرسون بين أبعاد منهجية ستة سيجما وأبعاد جودة الحياة}

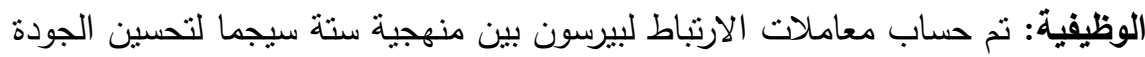
وخفض التكاليف بأبعادها ( خطوات منهجية ستة سيجما - نطبيق منهجية ستة سيجما-

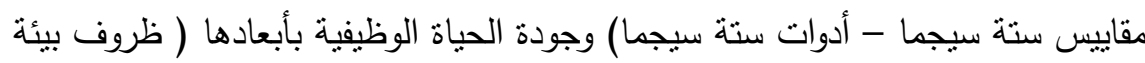
العمل - الخصائص الوظيفية - جماعة العمل - أسلوب الرئيس فى الأشراف - 
المشاركة فى إتخاذ القرارات )، يعرض جدول رقم (Y) معاملات ارتباط بيرسون بين أبعاد منهجية ستة سيجما لتحسين الجودة وخفض التكاليف وأبعاد جودة الحياة الوظيفية : جدول: معاملات الارتباط لبيرسون بين أبعاد منهجية ستة سيجما وأبعاد جودة الحياة الوظيفية

\begin{tabular}{|c|c|c|c|c|c|}
\hline مقاييس ستة & سأدوات ستة & منهجية سنتة & منهجية ستة & منهجية ستة & \\
\hline $.949 * *$ & $.616 * *$ & $.840 * *$ & $.727 * *$ & $.912 * *$ & جودة الحياة الوظيفية \\
\hline $.972 * *$ & $.604 * *$ & $.825 * *$ & $.751 * *$ & $.917 * *$ & ظروف بيئة العمل \\
\hline $.940 * *$ & $.625 * *$ & $.841 * *$ & $.687 * *$ & $.901 * *$ & الخصائص الوظيفية \\
\hline $.946 * *$ & $.644 * *$ & $.845 * *$ & $.740 * *$ & $.925 * *$ & جماعة العمل \\
\hline $.695 * *$ & $.422 * *$ & $.692 * *$ & $.553 * *$ & $.683 * *$ & أسلوب الرئيس في الأثراف \\
\hline $.982 * *$ & $.650 \% *$ & $.809 * *$ & $.752 * *$ & $.931 * *$ & المشاركة في إتخاذ القرارات \\
\hline .000 & .000 & .000 & .000 & .000 & Sig. $(2-$ tailed $)$ \\
\hline 203 & 203 & 203 & 203 & 203 & $\mathrm{~N}$ \\
\hline
\end{tabular}

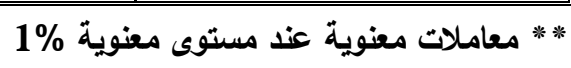

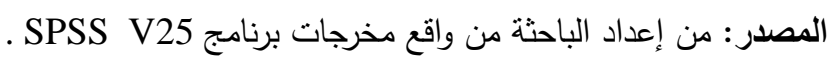

ويتضح من الجدول رقم (r)

• وجود ارتباط طردي قوي بين (مقاييس ستة سيجما) كأحد أبعاد منهجية ستة سيجما لتحسين الجودة وخفض التكاليف و (المشاركة فى إتخاذ القرارات) كأحد أبعاد جودة الحياة لئنة

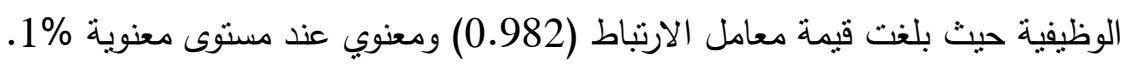
• وتوجد علاقة طردية قوية بين (مقاييس ستة سيجما) كأحد أبعاد منهجية ستة سيجما لتحسين الجودة وخفض التكاليف و (ظروف بيئة العمل ) كأحد أبعاد جودة الحياة الوظيفية حيث بلغت قيمة معامل الارتباط (0.972) ومعنوي عند مستوى معنوية 1\% وكانت أقل قيمة لمعامل الارتباط بين (أدوات ستة سيجما) كأحد أبعاد منهجية ستة التة

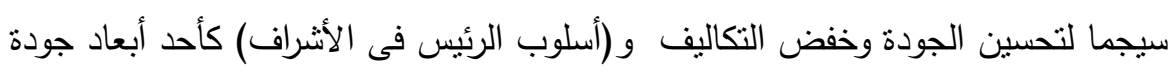
الحياة الوظيفية حيث بلغت قيمة معامل الارتباط (0.422) • مما سبق يدل صحة الفرض الرئيسي الأول وصحة الفرض البديل لا يوجد اثر جوهري

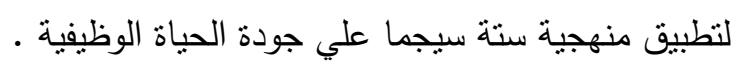

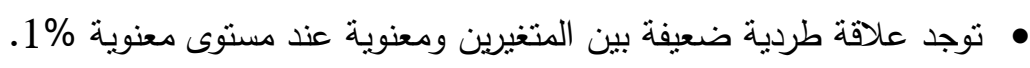

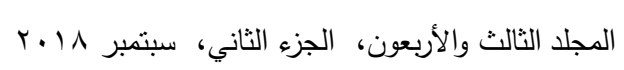


> تقديرات نموذج الإنحدار الجزئى لانحدار المتغير التابع الأول ( متوسط آراء عينة الاراسة حول جودة الحياة الوظيفية ) على المتغيرات المستقلة (أبعاد منهجية ستة الإنة سيجما لتحسين الجودة وخفض التكاليف):

جدول: معاملات ارتباط بيرسون بين أبعاد منهجية ستة سيجما وتكاليف جودة الحياة الوظيفية

\begin{tabular}{|c|c|c|c|c|c|}
\hline ستة سيجما & سوات ستة & منهجية ستثة & منهجية ستة & ستة سيجما & \\
\hline $.889 * *$ & $.576 * *$ & $.792 * *$ & $.676 \% *$ & $.853 * *$ & تكاليف جودة الحياة \\
\hline $.972 * *$ & $.674 * *$ & $.775^{* * *}$ & $.726 * *$ & $.922 * *$ & الأختيار والتعيين \\
\hline $.806 * *$ & $.503 * *$ & $.739 * *$ & $.636 * *$ & $.777 * *$ & خفض تكاليف \\
\hline $.564 * *$ & $.338 * *$ & $.571^{* * *}$ & $.428 * *$ & $.548 * *$ & المكافأت الكاليفوافز \\
\hline .000 & .000 & .000 & .000 & .000 & Sig. (2-tailed) \\
\hline 203 & 203 & 203 & 203 & 203 & $\mathbf{N}$ \\
\hline
\end{tabular}

نتائج اختبار الفرض الثانى:

ه ب بتضح عدم صحة الفرض الثانى وصحة الفرض البديل:

ه " يوجد أثر جوهري لمنهجية ستة سيجما على تكاليف جودة الحياة الوظيفية "

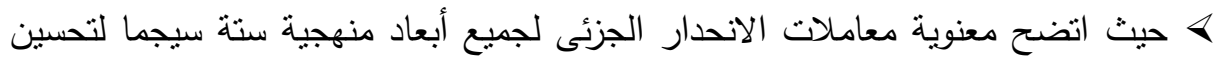
الجودة وخفض التكاليف ماعدا معامل خطوات منهجية ستة سيجما و (أدوات ستة

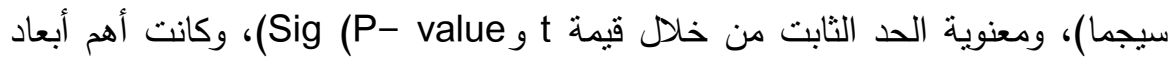
منهجية ستة سيجما لتحسين الجودة وخفض التكاليف التى تؤثر فى تكاليف جودة الحياة

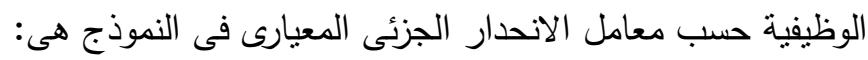
> > مقاييس ستة سيجما.

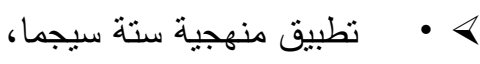




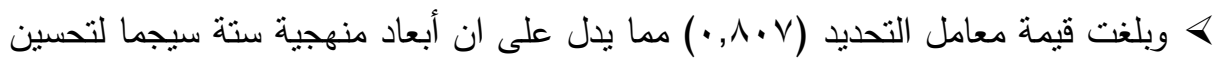

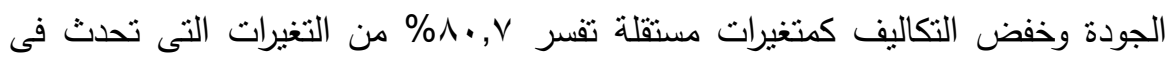

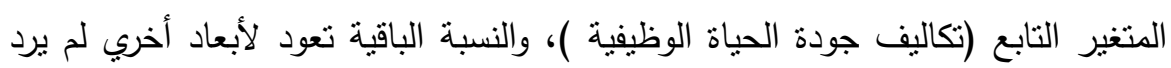

$$
\text { ذكرها في النموذج. }
$$

ويتضح مما سبق وجود تأثثر معنوي لأبعاد منهجية ستة سيجما على تكاليف جودة الحياة الوظيفية

الإحصاء الوصفى لآراء العاملين بمستثفيات جامعة عين شمس لمتغيرات الاراسة حسب

\begin{tabular}{|c|c|c|c|c|}
\hline \multicolumn{4}{|c|}{ سنوات الخبرة } & \\
\hline الانحراف المعياري & الحستوسط & التكرار & & \\
\hline .464 & 3.4295 & 39 & أقل من 5 سنة & \multirow{3}{*}{ |منهجية ستة سيجما | } \\
\hline .792 & 3.6351 & 121 & من 5 إلى أقل من 15 سنة & \\
\hline .422 & 3.9192 & 43 & من 15 سنة فأكثر & \\
\hline .672 & 3.1643 & 39 & أقل من 5 سنة & \multirow{3}{*}{ جودة الحياة } \\
\hline 1.045 & 3.4481 & 121 & من 5 إلى أقل من 15 سنة & \\
\hline .304 & 4.0456 & 43 & من 15 سنة فأكثر & \\
\hline .588 & 3.0965 & 39 & أقل من 5 سنة & \multirow{3}{*}{ |تكاليف جودة الحياة } \\
\hline .829 & 3.3479 & 121 & من 5 إلى أقل من 15 سنة & \\
\hline .754 & 3.7895 & 43 & من 15 سنة فأكثر & \\
\hline
\end{tabular}

$$
\text { نتائج اختبار الفرض الثالث: }
$$

ه أظهرت النتائج أنه " لا توجد فروق بين متوسط آراء عينة العاملين بمستشفيات جامعة عين شمس لمتغيرات الدراسة تعزي للمتغيرات الديموغرافية المتمثلة في ( النوع - المستوي تُوني

$$
\text { الوظيفي) }
$$

بينما يوجد إختلاف معنوى بين منوسط آراء عينة الدراسة حول متغيرات الدراسة حسب

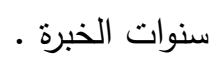

ه مما سبق ينضح صحة الفرض الصفري الثالث جزئياً والذي ينص علي " لا يوجد إختلاف هنوات جوهرى بين أراء عينة الدراسة حول متغيرات الدراسة تعزى للمتغيرات الديموغرافية المتنتلة

$$
\text { فى (النوع- المستوى الوظيفى). }
$$

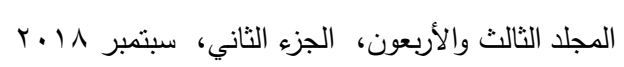


ه " وعدم صحة الفرض البديل: " يوجد إختلاف جوهرى بين أراء عينة الدراسة حول متغيرات الدراسة تعزى للمتغيرات الديموغرافية المتمنلة فى (النوع- المستوى الوظيفى)."

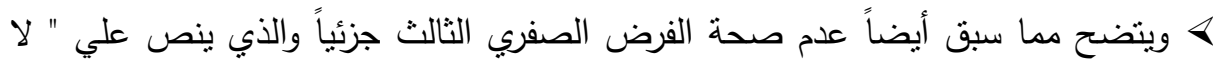
يوجد إختلاف جوهرى بين أراء عينة الدراسة حول متغيرات الدراسة تعزى للمتغيرات الايموغرافية المتمنظة فى (سنوات الخبرة).

ه " وصحة الفرض البديل: " يوجد إختلاف جوهرى بين أراء عينة الدراسة حول متغيرات

$$
\text { الدراسة تعزى للمتغيرات الديموغرافية المتمنلة فى (سنوات الخبرة)." }
$$

يعرض جدول رقم (5/34) وشكل رقم (5/3) تقديرات نموذج الإنحدار الجزئى لانحدار المتغير التابع الأول ( منوسط آراء عينة الدراسة حول جودة الحياة الوظيفية ) على المتغيرات المستقلة (أبعاد منهجية ستة سيجما لتحسين الجودة وخفض التول منوسطة التكاليف): جدول: تقديرات نموذج الانحدار الجزئى لانحدار المتغير التابع الأول (جودة الحياة الوظيفية )

\begin{tabular}{|c|c|c|c|c|c|c|}
\hline \multirow[b]{2}{*}{ الترتيب } & \multicolumn{5}{|c|}{ التقديرات } & \multirow[b]{2}{*}{ المتغيرات المستقلة } \\
\hline & Sig. & $\mathbf{t}$ & الجزئمى لمعيارى الانحدار & الانحدار & المعياري & \\
\hline- & .945 & $-.069-$ & & $-.009-$ & .130 & الحد الثابت \\
\hline- & .028 & 2.211 & .065 & .091 & .041 & خطوات منهجية ستة سيجما \\
\hline 2 & .000 & 4.991 & .178 & .227 & .045 & تطبيق منهجية سنة سيجما \\
\hline 3 & .008 & $-2.676^{-}$ & $-.076^{-}$ & $-.081-$ & .030 & أدوات ستة سيجما \\
\hline 1 & .000 & 17.861 & .809 & .774 & .043 & مقاييس ستة سيجما \\
\hline \multicolumn{7}{|c|}{ الخطأ=0.26405 } \\
\hline
\end{tabular}

المصدر: من إعداد الباحثة من واقع مخرجات برنامج SPSS V25 يتضح من الجدول رقم (r) والثكل رقم (5/20) معنوية نموذج الإنحدار المقدر عند

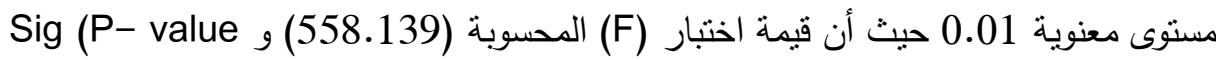
(0.000 = أقل من مستوى المعنوية، ويتضح من الجدول معنوية معاملات الانحدار الجزئى لجميع أبعاد منهجية ستة سيجما لتحسين الجودة وخفض التكاليف ماعدا معامل خطوات منهجية ستة سيجما وعدم معنوية الحد الثابت من خلال قيمة t و Sig (P- value)، وكانت إنانيا 
أهم أبعاد منهجية ستة سيجما لتحسين الجودة وخفض التكاليف التى تؤثر فى جودة الحياة

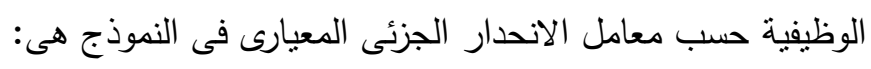
• مقاييس ستة سيجما.

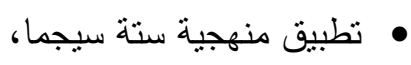
• أدوات ستة سيجما.

وبلغت قيمة معامل التحديد (0.919) مما يدل على ان أبعاد منهجية ستة سيجما

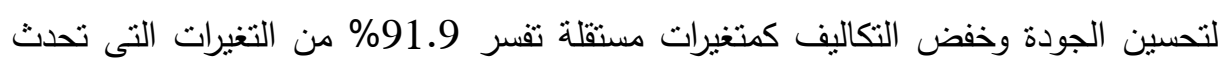

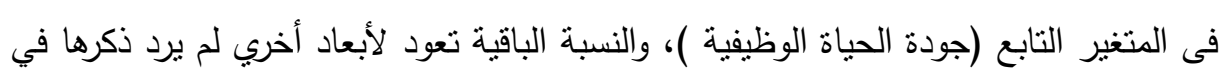
النموذج.

\section{ويتضح مما سبق وجود تأثير معنوي لأبعاد منهجية ستة سيجما على جودة الحياة}

الوظيفية مما سبق يتضح عدم صحة الفرض الأول وصحة الفرض البديل والذي ينص علي أنه: "

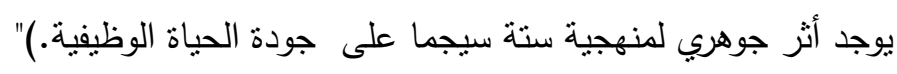
مناقشة النتائج: أهم نتائج الدراسة من وجهة نظر عنئه سينة الدراسة: •بتضح أن عينة الدراسة تعتقد في نطبيق مستثفيات جامعة عين شمس للمتغير المستقل (منهجية ستة سيجما لتحسين الجودة وخفض التكاليف، كأداة لخفض تكاليف جودة الحياة الوظيفية

• ويتضح أن عينة الدراسة تعتقد في نطبيق مستشفيات جامعة عين شمس للمتغير التابع

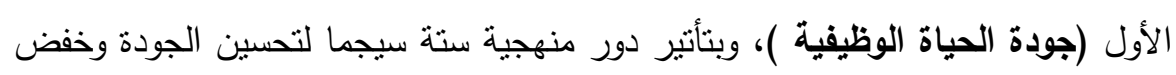

• كما يتضح أن عينة الدراسة تعتقد في تطبيق مستشفيات جامعة عين شمس للمحور (تكاليف جودة الحياة الوظيفية) والذي يمنل المتغير التابع الثاني، وبتأثير منهجية ستنة سيجما لتحسين الجودة وخفض التكاليف 
ويمكن ترتيب أهم متغيرات الدراسة من حيث ارتفاع متوسط الآراء كما يلى:

1- المتغير المستقل (منهجية ستة سيجما).

r- المتغير التابع الأول (جودة الحياة الوظيفية ):

r- المتغير التابع الثاني(تكاليف جودة الحياة الوظيفية):

• ارتفاع متوسط الآراء حول العنصر (حصول الموظفين على التدريب والتطوير للمهارات

فى مكان العمل بشكل منتظ .) كأحد عناصر خفض تكاليف التنريب بمنوسط (3.97)

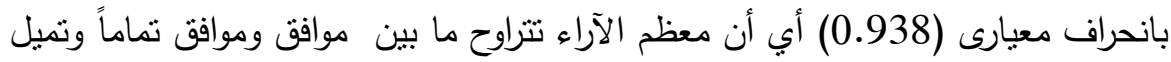

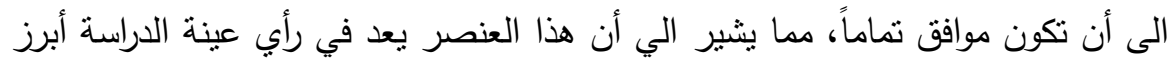
مؤشرات تطبيق مسنتفيات جامعة عين شمس للبعد (خفض نكاليف التدريب) كأحد أبعاد (تكاليف جودة الحياة الوظيفية)، وكنتيجة لأثر منهجية ستة سيجما لتحسين الجودة

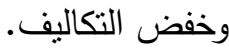
• أهمية دور منهجية ستة سيجما لتحسين الجودة وخفض التكاليف بت جودة الحياة الوظيفية

في زيادة قدرة المستشفيات التتافسية والتي بدورها تدعم تكاليف جودة الحياة الوظيفية .

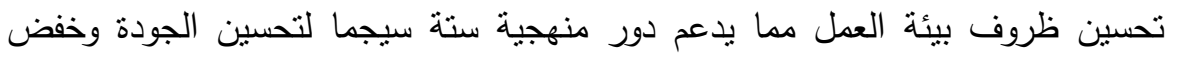
التكاليف، ومن ثم جودة الحياة الوظيفية. تحرص إدارة المستشفيات على تطبيق منهجية ستة سيجما لتحسين الجودة وخفض التكاليف، وذلك لخفض نكاليف التدريب)، كأحد أبعاد تكاليف جودة الحياة الوظيفية.

\section{اللزوكيايت}

ا ـ أهمية دور منهجية ستة سيجما لتحسين الجودة وخفض التكاليف بت جودة الحياة الوظيفية

في زيادة قدرة المستشفيات التتافسية والتي بدورها تدعم تكاليف جودة الحباة الوظيفية . r. تحسين ظروف بيئة العمل مما بدعم دور منهجية ستة سيجما لتحسين الجودة وخفض التكاليف، ومن ثم جودة الحياة الوظيفية. 


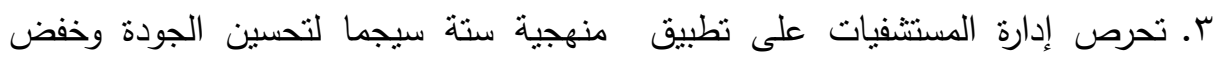
التكاليف، وذلك لخفض تكاليف التدريب)، كأحد أبعاد تكاليف جودة الحياة الوظيفية

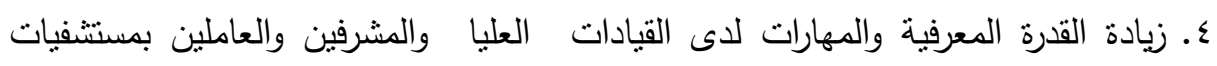
جامعة عين شمس. ه. ضرورة توفير مناخ تتظيمى يسمح بالإبتكار والإبداع لكافة المستويات الإدارية والوظائف النمطية بالمستشفيات ،وذلك من خلال تجريب الأفكار والحلول الإبتكارية التى يقدمها

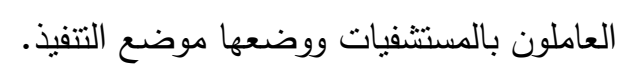

7. تتمية وتقوية العلاقات الشخصية بين القيادات والعاملين داخل المسنشفيات. V. خلق مناخ مناسب يتسم بالثقة بين الرؤساء ومرؤوسهم وذلك من خلال إتباع مبدأ الثنفافية

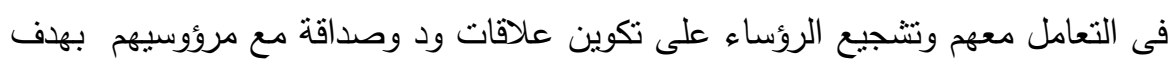
تحسين ظروف بيئة العمل بالمستشفيات.

\section{المرالية}

أسعد حماد أبومازن: "العلاقة بين الدعم التتظيمي المدرك والإلتزام التنظيمي"، دراسة ميدانية

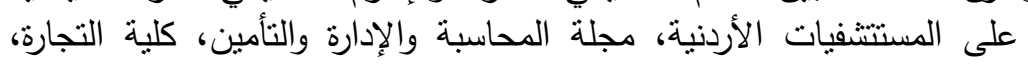

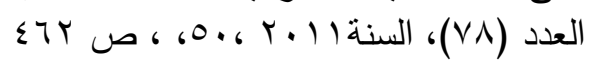

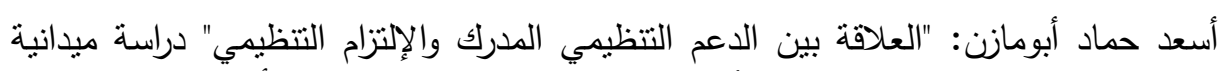

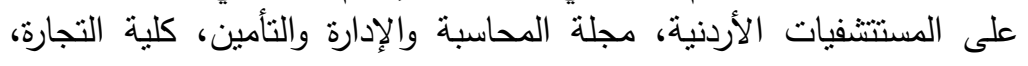

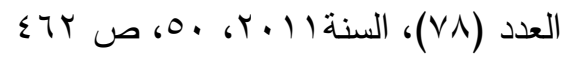

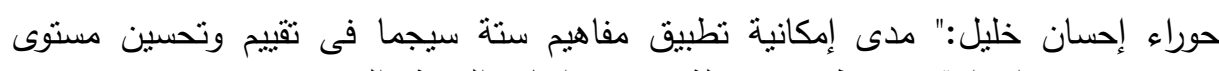

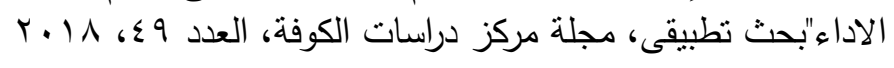

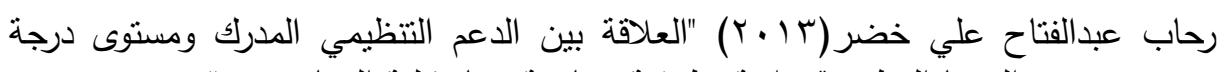

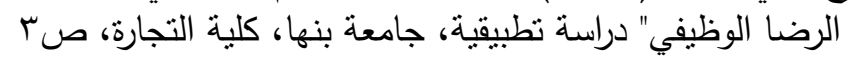

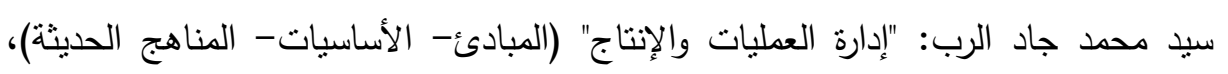

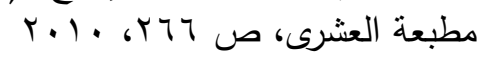

سيد محمد جاد الرب: "جودة الحياة الوظيفية في منظمات الأعمال المصرية"، مطبعة العشري،

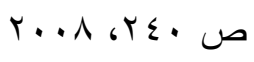

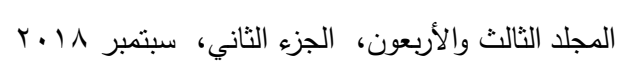




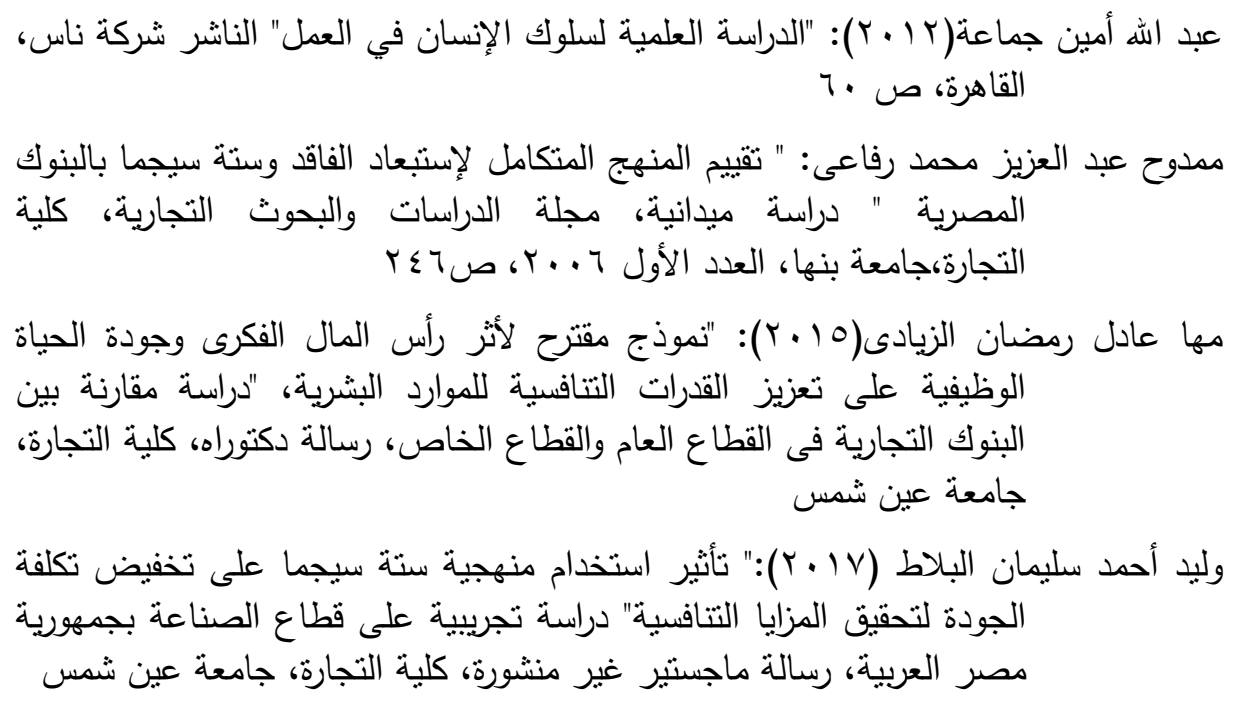

Akhil Khaguria ( 2018) implementation of DMAIC Six Sigma Principle in There performing of improving rate of Production (,international Journal For Research in Mechanical Civil Engineering :issN:2203-2727; Vol(4).

Chowm A, Finney T and Woodford K(2010). "Training Design and Transfer contributions of Six Sigma" International Journal of productivity and performance management, Vol. 7 pp, 182-195.

Indumathi G. S., Selvan R. Thamil (2014): Quality of Work. Life and Self Evaluation of Performance: Parameters at Work Place. "International Journal of Research in Commerce and Management", January; Vol,5.Iss.1,pp.22- 24.

James, Derrell S August,( 2005) using lean and Six Sigma in Project, Management: Quality Digest Magazine, p.p. 1-5, from www.quality digest.com.

Motorola University (2007) "What is six Sigma", Six Sigma", Six Sigma Dictionary, \& the inventors of six Sigma, Retrieved at Dec. 11, 
Osamin Dobbin (2017) "Pursuing Perfection in the Romanian Healthcare System While Applying Len Six Sigma Methodology" Proceedings Of The international Management Conference the Role of Management in The Economic Paradigm of the century November ,Bucharest, Romania.

SPTI, CDOC, Roadmap, Six Sigma, Breakthrough, and Beyond Quality Journal Institute, Retrieved at Dec. 12.

\title{
MEASURING THE EFFECT OF SIX SIGMA APPROACH ON COSTS OF QUALITY OF THE WORKING LIFE - A FIELD STUDY
}

\author{
Refea, M. A ${ }^{(1)}$; Ragab, M. H. ${ }^{(2)}$; El-shahat, Nihal, M. F. ${ }^{(2)}$ \\ and Ali, Nabiha, M. B.
}

1) Faculty of Commerce, Ain Shams University 2) Institute of Environmental Studies \& Research, Ain Shams University

\begin{abstract}
This study purpose is to measure the impact of six sigma methodology on quality of the work life, applying it on the employees in Ain Shams University Hospitals; and identifying as well the importance and mechanisms of applying such methodology in addition to recruiting an applied study for identifying the appropriateness, potentialities and demands of application on Ain Shams University Hospitals the suggested for this study.

For achieving this study aims, a questionnaire form is designed, distributed and collected through interview and included a set of phrases for measuring the study sample attitudes towards the study variables. The researchers count on a mixture between the deductive and the inductive method through the theoretical and the field study.
\end{abstract}

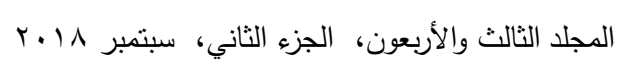


Researchers have administered a data analysis employing Kruskal Test for each question in the investigation form for testing validity of the study hypotheses. The study sample consists of (200) items which is the number of the correct retrieved forms. Researchers come to several results and recommendations concerning the study sample (Ain Shams University Hospitals.

The study comes to that the application of six sigma methodology on Ain Shams University's Hospitals leads to improvement of work quality of life.

\section{The study recommends the following:}

1- The importance of the six sigma methodology in improving quality and reducing costs of quality of work life in increasing the ability of the competitive ability of hospitals that support in turn the costs of the work life quality.

2- Improving the circumstances of the work environment which supports in turn the role of the six sigma methodology for improving quality and reduce costs and so the work quality 